\title{
NEW TECHNOLOGY OF THE SEARCHING OF THE DIAMOND BEARING KIMBERLITES METHODOLOGICAL BASIS AND FIELDS OF APPLICATIONS.
}

Garanin, V.K. and Kudrjavtseva, G.P.

Geological Department of Moscow State University, 119899, Lenin's Hills, Moscow, USSR.

The development of diamond deposits and searching for the new ones in Archangelsk and Jakutian kimberlite provinces, industrial developrent of the deep horizons on the working pit as well as retesting of the numerous kimberlite bodies in the Jakutian diamond bearing province facilitate the need for the devepolment and active usage of the mineralogical methods of the evaluation of the kimberlite diamond bearing. New mineralogical criteria for the searching of the diamond deposits have been offered by the laboratory working on the problems of the diamond deposits of the Geological Department of Moscow University. These methods together with remote sensing methods form the basis of the new technology of the diamond deposits searching.

The complex methudology of diamond bearing evaluation is based on the two groups of the mineralogical criteria.

The first group of eriteria allows to evaluate the potential diamond bearing of the object. They are based on the typomorphism of the mantle minerals from the inclus:uris in life diamond, intergrowths with it, from the diamond bearing peridotites,pyroxenites and eclogites as well as on the typomorphic peculiarities of the chrome spinels composition and picroilmenite from the ground mass of the kimberlite rocks. The criteria of this group are necessary but not sufficient to define the tested object as a diamond bearing one.

The second group of the mineralogical criteria defines the degree of the diamond crystals preservation during their delivery to the surface by the kimberlite system. The slow rate of xenogenous material raise, including diamond in the conditions of the increasing influence of the oxidation potential and alkaline-carbonate melt in the conditions of the increased temperatures facilitates the "burning" of the diamond and leads to the decrease of the kimberlite diamond bearing. The same conditions effect the chemical and phase composition of rineralssattelites of the diamond (MSD) and microcrystallic spinels and ilmenite from the ground mass of kimberlites.

The most contrast changes are connected with the formation of the kelyphite rims on the garnets and rims of replacement on the grains of olivine, chromediopside, ilmenite, chrome spinel arid other minerals by the formation of the resorbed surfaces on the MSD grains with the characteristic shapes of the microrelief, with the wide developrent of the decomposition solid solutiun structures in the MSD grains, with the formation of the different set of minerals in the kimberlite cement as a result of replacement and of fractioning of the kimberlite magma (chrome spinels of varying composition, titanomagnetite, manganese picroilmenite, rutile and perovskite).

The mass crystallization of perouskite shows the high alkalinity of mineral formation surroundings and directly defines the poor diamond bearing of the tested object. 
The priority of the mineralogical criteria of the diamond bearing deposits searching developed in this laboratory is protected legally by a series of the authors certificates and their efficiency is tested on the several objects of the Archangelsk and Jakutian diamond bearing provinces.

The complex methodology is realised on the basis of the analytical complex, including the automated systems for the analysis, processing, storage and accumulation of the newly input information (Eig.1). The technological process provides the highly efficient express and local analysis of morphology, physical properties, chemical and phase composition of minerals. The data bank for all the most important MSD has been set up and realised to develop the chemico-geological MSD classification both from the xenolithes of the depth rocks and from the ground mass of kimberlites, to define the typomorphism of minerals from the diamond paragenesis and the usage ofthis information to solve different search-evaluation problems.

The results of cluster analysis together with the available mineralogical information allowed set up chemico-genetical classifications for MSD with the extraction of typochemical features of the diamond paragenesis. The defining laws for sorting out (according to the types) the mineral paragenesis of newly incoming mineral analysis were calculated on the basis of discriminant analysis. The whole package of programmes with graphical supplement for the statistical processing of the results of the MSD investigation on the personal computers was set up.

The chemico-genetical MSD classifications are the basis for the effective work of the complex methodology with the application of the automated systems. The essence of the methodology, which has been realized on the new chemico-genetical classification of MSD with usage of the MSD data base in the combination with mighty analytical complex, lies in the complex study of diamond minerals-sattelites by different methods on the basis of the complex of mineralogical criteria of diamond bearing with the purpose to show the preservation of mineral parageneses, statistical spreading along the deposit, extraction among them the diamond bearing parageneses. The advantage of the methodology is achieved by the increase of evaluation reliability of the kimberlite ore bearing as a result of the complex approach, i.e. not only on one, but on the complex of signs considering not only the possibilities of the diamond crystal formation but also its preservation in the process of delivery to the surface. 


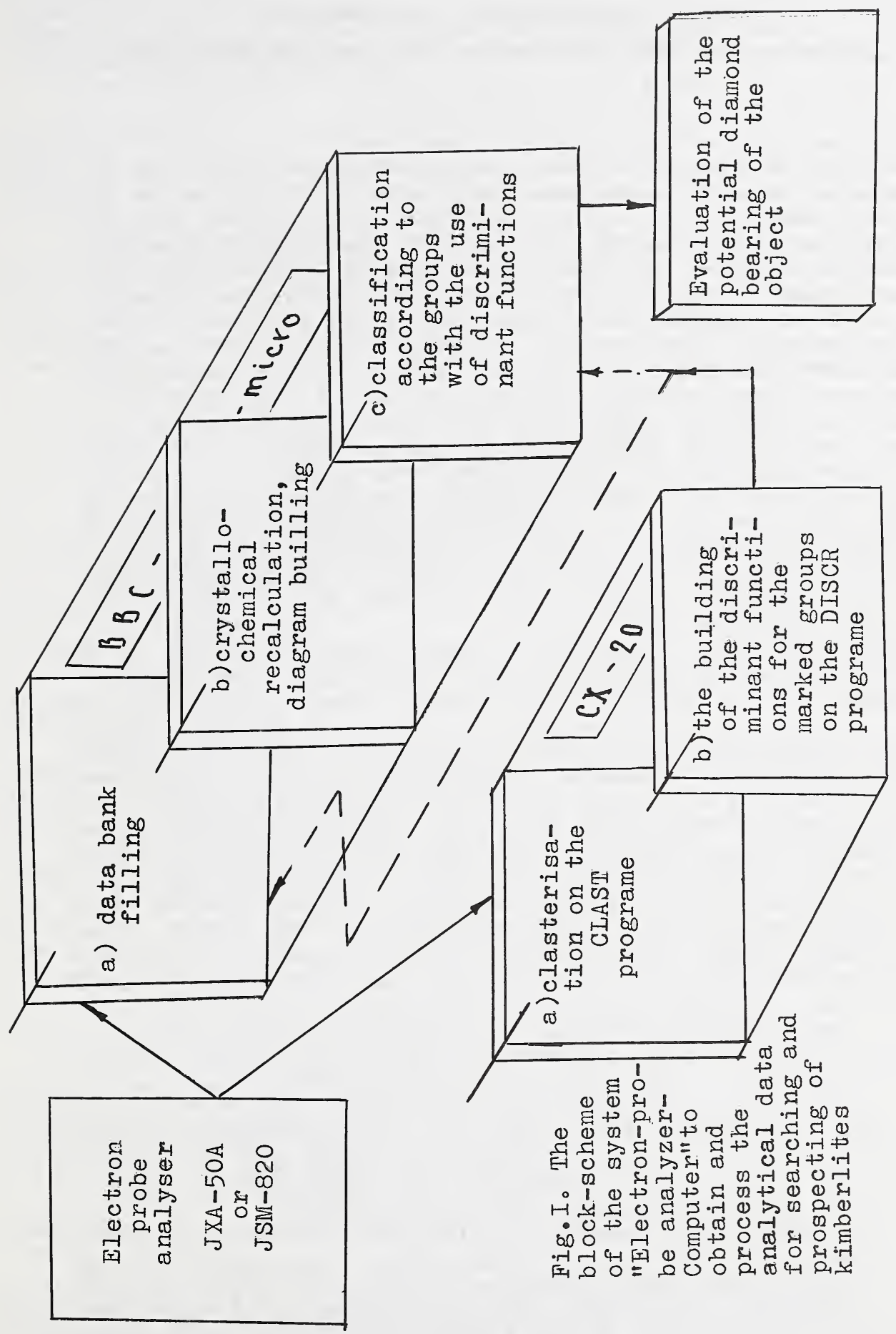

